\section{PERSISTENT BARN SWALLOWS AT SYLVAN LAKE}

W.B. PARSONS, Box 418, Sylvan Lake, Alberta. TOM $1 Z 0$

Three years ago I had a major problem with Barn Swallows. Each time I took my little tractor out of the shed to cut the grass, they started to build on the rafters. Before I was aware of it, the mud nest was half built. From then on, whenever I opened the door, they flew in. So I closed the door whenever I took the tractor out. The droppings did not look attractive on the tractor.

For the next two summers the birds tried to get into the shed whenever I opened the door; however, I won out. They built on a light fixture adjacent to the small door of the shed (Fig. 1). Then this August, after I had been away for a few days, whenever I opened the door, I had the impression of something flying out. Several days passed before I was sure; then I took a belated look up at the rafters. The nest had been completed and a bird was peering over the lip of it.

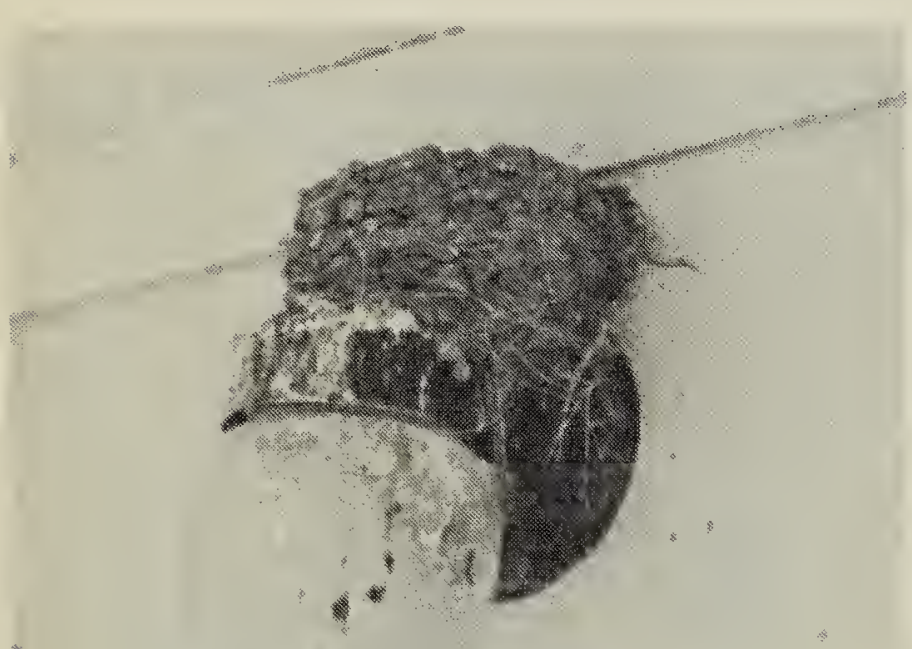

Figure 1. Barn Swallow nest.

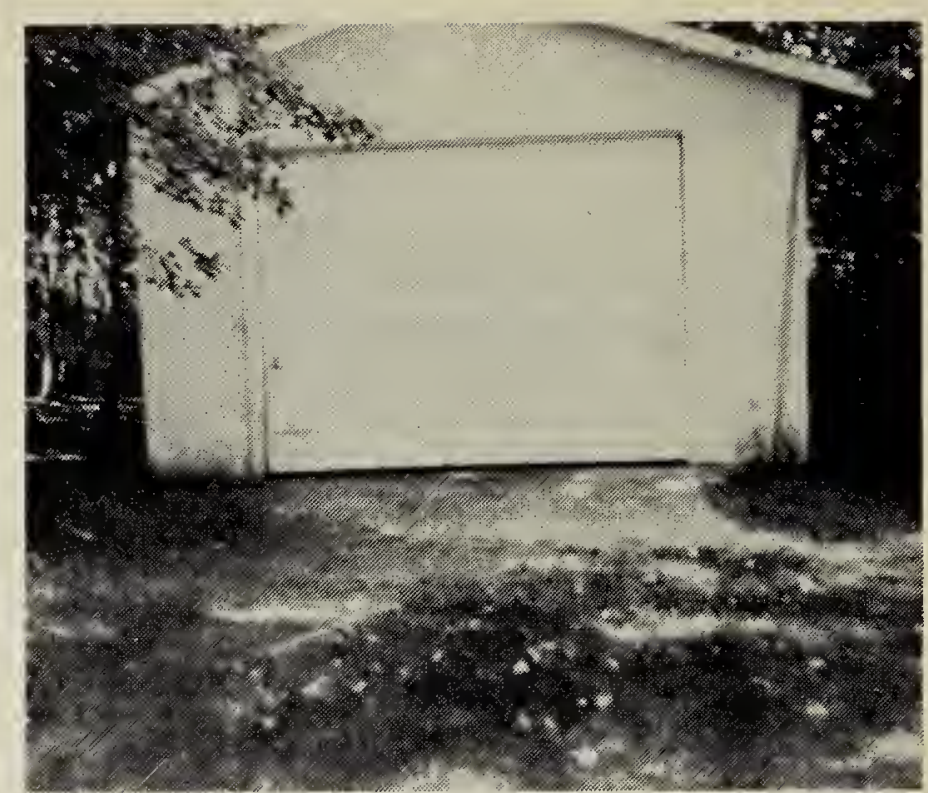

Figure 2. Gap under shed door.

I could not figure out how they got in until I closed the door and saw that there was a slight gap between the bottom of the door and the cement (Fig. 2). This was made during the winter when the weather strip froze to some ice and was torn off. The birds had sneaked in via this 1.5 in. $(4 \mathrm{~cm})$ gap, and had completed their nest.

It was too late to do anything about it; obviously there were eggs in the nest and I was going to have some cleaning up to do. I didn't climb up to count the eggs or the young but I watched. I saw the parent birds carrying food under the door. On 9 September when I went into the shed, the five young were on the rafter as shown in the picture (Fig. 3). Two days later they were gone.

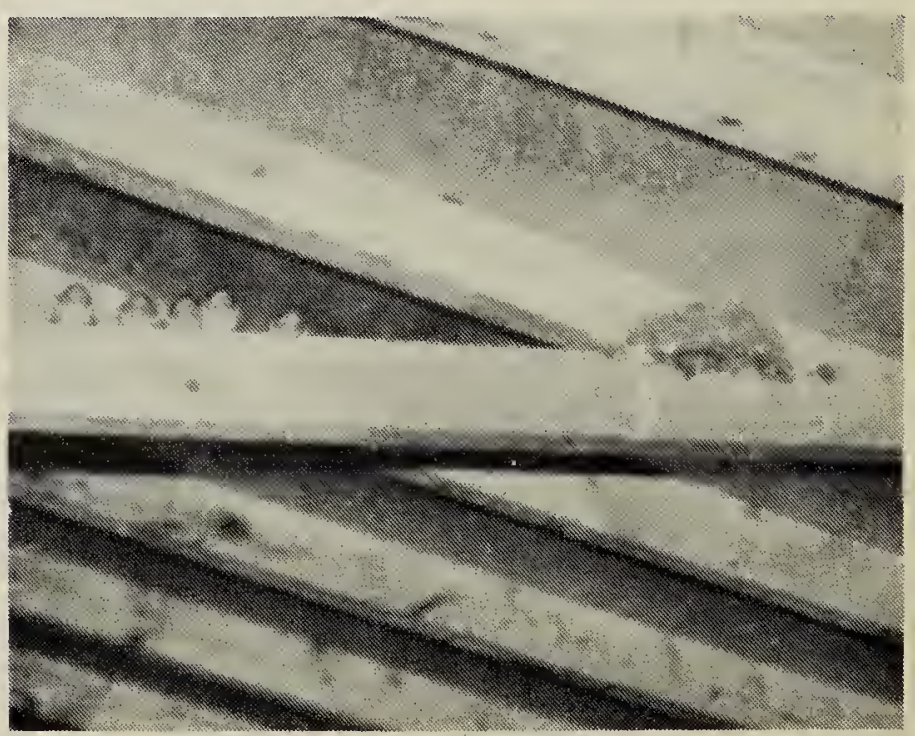

Figure 3. Fledgling Barn Swallows. 